\title{
Kajian Biblika Teologi Meminta Menurut Injil Matius 7:7-11 Dan Implikasinya Bagi Orang Percaya
}

\author{
Rizky Prakarsa Satria, Robi Panggarra
}

\begin{abstract}
Abstrak
Sesuai dengan latar belakang masalah yang ada, maka yang menjadi tujuan dalam penulisan skripsi ini adalah: Pertama, untuk menjelaskan teologi yang terkandung dalam pengajaran Yesus tentang meminta menurut Injil Matius 7:7-11. Kedua, untuk menjelaskan implikasi teologi pengajaran Yesus tentang meminta bagi kehidupan orang percaya. Metode penulisan yang digunakan adalah hermeneutika metode eksegesis Alkitab, yang sumbernya berlangsung dari literatur (Library Research) dengan menggunakan buku-buku pendukung yang relevan dengan judul yang dibahas oleh penulis dan disertai bantuan media elektronik. Adapun kesimpulan skripsi "Kajian Biblika Teologi Meminta Menurut Injil Matius 7:7-11 Dan Implikasinya Bagi Orang Percaya" dalam implikasi teologis adalah: Pertama, meminta adalah kehendak Allah, karena hal meminta merupakan perintah Tuhan. Kedua, meminta merupakan sikap ketaatan kepada Allah, karena merupakan sikap tunduk manusia kepada perintah-Nya yang menunjukkan ketaatannya kepada Allah. Dan kesimpulan skripsi ini dalam implikasi praktis adalah: Pertama, permintaan merupakan penyandaran diri kepada Tuhan, karena kesadaran manusia akan ketidakmampuannya dan membutuhkan pertolongan Tuhan. Kedua, permintaan terintegrasi dengan usaha pencapaian. Ketiga, permintaan harus berfokus pada Kerajaan Allah. Keempat, permintaan harus berfokus pada hal yang baik.
\end{abstract}

Kata Kunci: Meminta, Mencari, Mengetok, Matius 7:7-11

\section{Pendahuluan}

\section{Latar Belakang Masalah}

Yesus dalam khotbah-Nya di bukit menantang setiap orang untuk meminta kepadaNya seperti yang tertulis dalam Injil Matius 7:7-8 (TB),

"Mintalah, maka akan diberikan kepadamu; carilah, maka kamu akan mendapat; ketoklah, maka pintu akan dibukakan bagimu. Karena setiap orang yang meminta, menerima dan setiap orang yang mencari, mendapat dan setiap orang yang mengetok, baginya pintu dibukakan."

Dalam ayat ini menurut Ferguson bahwa tema khotbah Yesus tampak berubah dengan agak mendadak dan dikatakan bahwa para pengamat Alkitab menyatakan bahwa mata rantai yang menghubungkan bagian ini dengan bagian sebelumnya sama sekali tidak jelas, dari 
tema mengenai penghakiman serta pemilahan kepada tema mengenai doa. ${ }^{1}$ Sehingga dalam membahas ayat ini, sering kali terlepas dari tema sebelumnya, terlebih lagi dalam ayat ini tidak diberitahukan mengenai hal apa saja yang perlu diminta. Maka tanpa adanya batasan dan terlepasnya dari tema sebelumnya menyebabkan munculnya berbagai macam penafsiran yang sangat luas akan nas ini, sehingga penulis merasa perlu meneliti bahwa apakah benar Yesus membebaskan secara luas tanpa adanya batasan permintaan yang secara khusus dimaksudkan.

Masalah lain yang dikemukakan oleh John Stott bahwa nas ini dihadapkan kepada keluguan janji-janji Yesus mengenai pemberian permintaan, sehingga orang mengajukan bebarapa keberatan, antara lain:

Pertama, berdoa itu tidak pantas, "Desakan untuk berdoa ini," demikan ada yang mengatakan, memberi gambaran palsu tentang Allah. hal ini mengacu bahwa Allah perlu diberitahu tentang apa yang dibutuhkan, padahal Yesus sendiri mengatakan pada bagian sebelumnya bahwa Bapa kita yang di surga mengetahui apa yang kita perlukan dan bagaimanapun juga akan memelihara kita. Sehingga mengapa harus menyangka bahwa Ia baru mau memberikan sesudah diminta? Apakah orang tua akan menunggu untuk memenuhi keperluan anaknya, sampai anak meminta kepada mereka? ${ }^{2}$

Kedua, berdoa itu tidak perlu, keberatan kedua ini timbul lebih dari pengalaman ketimbang dari teologi. Orang Kristen yang berpikir kritis mendapati, bahwa banyak orang di sekitar mereka hidup mulus tanpa berdoa. Mereka mendapat yang mereka perlukan karena mereka berusaha untuk itu, bukan karena mereka berdoa untuk itu. Dengan contoh: petani mendapat panen yang baik karena banting tulang, ibu mendapat bayinya berkat ilmu kedokteran, biaya rumah tangga dapat ditutup hasil jerih payah sang ayah dan anggota keluarga lain yang mencari nafkah, bukan karena berdoa. ${ }^{3}$

Ketiga, berdoa itu sia-sia, hal ini erat kaitannya dengan hal yang kedua, orang berpendapat bahwa berdoa tidak perlu adalah karena Allah memberikan sesuatu kepada mereka yang tidak berdoa. Dan bahwa berdoa itu sia-sia, karena Allah alpa memberikan sesuatu kepada mereka yang telah khusus berdoa untuk itu, seperti doa supaya lulus ujian, tetapi gagal, doa untuk kesembuhan, tetapi makin parah, doa untuk kedamaian, tetapi dunia penuh dengan gemuruh peperangan, sehingga berdoa itu percuma. ${ }^{4}$

Banyak orang Kristen yang berpegang pada janji ini yang merupakan jaminan bahwa setiap permintaan diberikan merupakan janji Tuhan bagi orang percaya yang meminta kepada-Nya. Namun dalam perjalanan kehidupan bagi sebagian besar orang yang berpegang pada janji ini tak jarang merasakan kekecewaan dari apa yang dimintanya tak kunjung diterima. Bahkan Millard dalam bukunya mengatakan dengan tegas bahwa "kita tidak selalu menerima apa yang kita minta." Perasaan kecewa pada setiap orang yang permintaan tidak tercapai seringkali nampak dalam kehidupan orang Kristen yang kemudian berakibat

${ }^{1}$ Sinclair B. Ferguson, Khotbah Di Bukit: Cermin Kehidupan Sorgawi Di Tengah Dunia Berdosa (Surabaya: Penerbit Momentum, 2009 ), 175.

${ }^{2}$ John R.W. Stott, Khotbah di Bukit (Jakarta: Yayasan Komunikasi Bina Kasih, 2008), 271.

${ }^{3}$ John R.W. Stott, Khotbah di Bukit, 272.

${ }^{4}$ Stott, 274.

${ }^{5}$ Millard J. Erickson, Teologi Kristen Volume Satu (Malang: Penerbit Gandum Mas, 2014), 651. 
meninggalkan kehidupan sebagai orang percaya yang mengandalkan Tuhan sebagai sumber pemenuhan segala kebutuhan setiap manusia, sehingga hal mengandalkan Tuhan mulai beralih menjadi mengandalkan manusia atau diri sendiri untuk segala pemenuhan kebutuhannya sebagai dampak dari kekecewaan akan pengharapan janji Tuhan yang tak kunjung diterimanya, seperti yang dikemukakan oleh Daniel Sutoyo dalam jurnalnya yang mengatakan bahwa beberapa orang Kristen lebih banyak menghabiskan waktu untuk bekerja, melakukan ini dan itu sehingga tidak ada waktu lagi untuk melakukan persekutuan maupun doa pribadi. ${ }^{6}$ Dengan jelas ini mencerminkan penyandaran akan diri sendiri sebagai akibat dari kekecewaan karena tidak menerima hal yang dimintanya. Hal ini juga dikemukakan oleh Nehemia Lauden dalam kaitannya dengan hal pengabulan doa yang mengatakan banyak orang menjadi tawar hati karena berpegang pada janji pengabulan doa bahwa semua permohonan akan dikabulkan, namun tidak terpenuhi. Ia mengatakan bahwa "Pada masa sekarang banyak orang Kristen pandangannya keliru tentang jawaban doa yang penuh kuasa. Dengan adanya pandangan orang Kristen yang salah maka keluar kata-kata seperti Tuhan tidak adil dalam menjawab doa manusia, Tuhan tidak mau menjawab doa manusia, Tuhan berjanji bahwa Ia akan menjawab doa manusia, Tuhan berjanji bahwa Ia akan menjawab doa setiap orang yang berseru dalam nama-Nya, tetapi orang Kristen zaman sekarang sedikit yang mangalaminya. Karena itu banyak orang Kristen yang merasa kecewa, ketiadaan pengharapan dan bahkan orang Kristen yang meninggalkan Tuhan Yesus yang adalah satusatunya penjawab doa bagi semua manusia di dunia."7 Sehingga janji pengabulan permintaan dalam doa kepada Tuhan ini terlihat mencakup hal yang sangat luas tanpa batasan yang diberikan dalam pengajaran Yesus di bukit yang akhirnya menimbulkan banyak penafsiran berbeda-beda, untuk hal ini penulis merasa perlu untuk mengetahui fokus permintaan sesuai dengan ajaran Yesus pada ayat ini.

Adapun masalah lain bahwa adanya perbedaan Injil Sinoptik yang tertulis dalam Matius 7:7-11 dengan Lukas 11:9-13 mengenai ikan dan ular pada Matius, namun pada Lukas mengganti dengan telur dan kalajengking, serta pada Matius berkata tentang pemberian yang baik, sedangkan dalam Lukas berkata tentang pemberian Roh Kudus. Sehingga penulis ingin mengetahui lebih dalam apakah hal yang diminta yang dimaksudkan Yesus berbicara tentang hal-hal umum seperti dalam Matius atau berbicara tentang hal-hal spiritual seperti dalam Lukas.

\section{Pokok Masalah}

Setelah melihat latar belakang masalah di atas, maka yang menjadi pokok masalah dalam karya tulis ini, yaitu:

Pertama, apa teologi yang terkandung dalam pengajaran Yesus tentang meminta berdasarkan Injil Matius 7:7-11?

Kedua, bagaimana implikasi teologi pengajaran Yesus tentang meminta bagi kehidupan orang percaya?

\footnotetext{
${ }^{6}$ Daniel Sutoyo. “Allah Memanggil Umat-Nya Untuk Menjadi Gereja Yang Tekun Berdoa Menurut Kisah Para Rasul 4:23-31" DUNAMIS: Jurnal Teologi dan Pendidikan Kristiani I, No. 1 (Oktober 2016): 53, diakses 20 Februari 2018, http://www.sttintheos.ac.id/ejournal/index.php/dunamis/article/viewFile/101/97

${ }^{7}$ Nehemia Lauden, "Peranan Doa Dalam Kehidupan Kristen Menurut Yakobus 5:13-20” (Skripsi, S.Th, Sekolah Tinggi Theologia Jaffray Makassar, 2000), 1.
} 


\section{Tujuan Penelitian}

Adapun yang menjadi tujuan penulisan karya ilmiah ini adalah sebagai berikut:

Pertama, untuk menjelaskan secara alkitabiah teologi pengajaran Yesus tentang meminta berdasarkan Injil Matius 7:7-11.

Kedua, untuk mendapatkan implikasi teologi pengajaran Yesus tentang meminta bagi kehidupan orang percaya.

\section{Manfaat Penelitian}

Adapun manfaat penulisan skripsi ini adalah sebagai berikut:

Pertama, agar setiap orang percaya memiliki pemahaman yang benar dari teologi meminta.

Kedua, untuk menjadi pedoman bagi penulis di dalam pelayanan.

Kedua, untuk memenuhi salah satu persyaratan akademik dalam mencapai gelar Sarjana Teologi di Sekolah Tinggi Theologia Jaffray Makassar.

\section{Metode Penelitian}

Adapun metode yang digunakan dalam penelitian ini adalah metode kualitatif. Metode penelitian kualitatif merupakan penelitian yang bersifat deskripsi, cenderung menggunakan analisis dan lebih menonjolkan proses makna. Dalam penelitian kualitatif data yang dikumpulkan lebih banyak huruf, kata ataupun gambar daripada angka. Dalam pembahasan skripsi ini, penulis melakukan penelitian dengan menggunakan eksegesis mengenai teologi meminta menurut Injil Matius 7:7-11. Gordon D. Fee dan Douglas Stuart mengatakan bahwa eksegesis adalah hal mempelajari dan membahas Alkitab secara sistematis dan teliti untuk menemukan arti asli yang dimaksudkan. ${ }^{8}$ Adapun menurut Hasan Susanto bahwa ada tiga bidang dalam menyelidiki arti kata, yaitu fonologi (ilmu suara kata), morfologi (ilmu bentuk kata), dan sematik (ilmu arti kata). ${ }^{9}$ Berdasarkan pengertian tersebut maka dalam menafsirkan sebuah teks Alkitab, perlu memperhatikan makna kata dalam sebuah kalimat atau teks agar maksud penulis teks tersebut dapat dimengerti. Sehingga penulis melengkapi pembahasan dalam bab ini dengan analisa kata yang akan mempermudah penulis dalam menafsir. Penulis merasa perlu memperhatikan setiap kata yang dianggap penting untuk diselidiki dalam sebuah teks. Sehubungan dengan hal ini maka dalam teks ini penulis memilih kata "meminta" untuk lebih mengerti Injil Matius 7:7-11.

Sesuai dengan pengertian tersebut, maka penulis akan melakukan analisa dan penelitian terhadap teks Injil Matius 7:7-11. Adapun teknik pengumpulan data yang digunakan adalah dengan melakukan penelitian kepustakaan (Library Research), terhadap berbagai sumber data antara lain: Alkitab, tafsiran-tafsiran, jurnal-jurnal dan buku-buku yang berhubungan dengan "meminta" serta menulis menggunakan metode eksegesis. Yang disusun secang berhubungan dengan "meminta" serta menulis menggunakan metode eksegesis. Yang disusun secara deskriptif untuk mencapai sasaran dan tujuan penulisan.

\footnotetext{
${ }^{8}$ Gordon D. Fee dan Douglas Stuart, Hermeneutika Bagaimana Menafsirkan Alkitab Dengan Benar. (Malang: Gandum Mas, 2000), 8.

${ }^{9}$ Hasan Sutanto, Hermeneutik Prinsip dan Metode Penafsiran Alkitab (Malang: Seminari Alkitab Asia Tenggara, 1998), 210-213.
} 


\section{Batasan Penelitian}

Dalam penulisan ini, penulis memberikan batasan tentang "meminta" yang berdasarkan Injil Matius 7:7-11. Adapun penambahan dari tafsiran dan teori-teori yang berkembang mengenai pokok bahasan penulis hanyalah dengan tujuan sebagai referensi dan acuan serta ide-ide untuk membantu memperlengkapi keabsahan dalam penulisan karya ilmiah ini.

\section{Kesimpulan}

Berdasarkan hasil uraian penulis dalam skripsi tentang analisis Injil Matius 7:7-11 teologi meminta dan implikasinya bagi orang percaya masa kini, maka penulis menarik kesimpulan sebagai berikut:

Pertama, meminta adalah kehendak Allah yang diperintahkan dan wajib dilakukan secara terus menerus dalam kehidupan orang percaya.

Kedua, meminta merupakan sikap ketaatan kepada Allah, dengan melakukan perintah-Nya secara terus menerus dengan penuh hasrat merupakan bentuk sikap ketaatan manusia kepada Allah.

Ketiga, permintaan merupakan bentuk penyadaran diri kepada Allah yang menyadari bahwa kehidupan membutuhkan peranan Tuhan dan mengandalkan Tuhan, sehingga setiap permintaan bagi orang percaya dapat dipandang sebagai kesempatan untuk melihat campur tangan Tuhan dalam menyatakan hadirat-Nya melalui pertolongan-Nya.

Keempat, permintaan terintegrasi dengan upaya pencapaian yang mempunyai hasrat yang kuat untuk mewujudkannya dengan daya upaya melalui usaha pencapaiannya yang penuh pengharapan.

Kelima, permintaan harus berfokus pada Kerajaan Allah yang memampukan untuk memiliki sikap moral yang sesuai dengan standar nilai Kerajaan Allah dan bagi perluasan Kerajaan Allah.

Keenam, permintaan harus berfokus pada hal yang baik dan tidak mengandung tipu muslihat keburukan, sehingga hal yang baik hanyalah yang sesuai dengan kehendak Allah dan untuk mendapati kehendak Allah, haruslah terlebih dahulu mendapati pribadi Allah yaitu dalam Roh Kudus-Nya.

\section{Kepustakaan}

Abineno, J. L. Ch. Khotbah Di Bukit. Jakarta: BPK Gunung Mulia, 2002.

Barclay, William. Pemahaman Alkitab Setiap Hari: Matius Ps.1-10. Jakarta: BPK Gunung Mulia, 2008.

Boland, B. J., P. S. Naipospos. Tafsiran Alkitab: Injil Lukas. Jakarta: BPK Gunung Mulia, 2008.

Brake, Andrew. Spiritual Formation: Menjadi Serupa Dengan Kristus. Bandung: Kalam Hidup, 2014.

Brown, Jeannine K. Teach The Text Commentary Series: Matthew. United State of America: Baker Publishing Group, 2015.

Burney, C. F. The Portry of Our Lord: An Examination of The Formal Elements of Hebrew Poetry in the Discourses of Jesus Chirst. Eugene: Clarendon Press, 1925. 
Chapman, Adina. Pengantar Perjanjian Baru. Bandung: Kalam Hidup, 2014.

Christian, Firman, AND Panggarra, Robi. "Makna Kata Ekklesia Berdasarkan Matius 16:18

Dan Implementasinya Dalam Kehidupan Orang Percaya Masa Kini" Jurnal

Jaffray [Online], Volume 9 Number 2 (1 October 2011)

Conner, K., J. Ken Malmin. Interpreting The Scroptures. Malang: Gandum Mas, 2004.

Davidson, Jo Ann. Toward A Theology Of Beauty: A Biblical Perspective. United States of America: University Press of America, 1984.

De Heer, J. J. Tafsiran Alkitab; Injil Matius 1 ( $f$ s. 1 s/d fs. 12). Jakarta: BPK Gunung Mulia, 1982.

Douglas, J. D. (ed.). Ensiklopedi Alkitab Masa Kini, Jilid I. Jakarta: Yayasan Komunikasi Bina Kasih/OMF. 2000.

Drewes, B. F. Satu Injil Tiga Pekabar. Jakarta: BPK Gunung Mulia, 1982.

Erickson, Millard J. Teologi Kristen Volume Satu. Malang, Penerbit Gandum Mas. 2014.

Fee, Gordon D., Douglas Stuart. Hermeneutika Bagaimana Menafsirkan Alkitab Dengan Benar. Malang: Gandum Mas, 2000.

Fee, Gordon D. Eksegesis Perjanjian Baru Edisi Ketiga: Sebuah buku pegangan bagi Masiswa dan Pelayan Gerejawi. Malang: Literatur SAAT, 2011.

Ferguson, Sinclair B. Khotbah Di Bukit: Cermin Kehidupan Sorgawi Di Tengah Dunia Berdosa. Surabaya: Penerbit Momentum, 2009.

Guthrie, Donald. Teologi Perjanjian Baru. Jakarta: BPK Gunung Mulia, 1993. Tafsiran Alkitab Masa Kini 3 Matius-Wahyu. Jakarta: BPK Gunung Mulia untuk Yayasan Bina Kasih/OMF, 1983.

Hakh, Samuel Benyamin. Pemberitaan Tentang Yesus Menurut Injil-Injil Sinoptik. Bandung: Jurnal Info Media, 2008, 11

Hayes, John H., Carl R. Holladay. Pedoman Penafsiran Alkitab. Jakarta: BPK Gunung Mulia, 2015.

Jarvis, Cynthia A., E. Elizabeth Johnson (General Editors). Feasting On The Gospels: Matthew, Volume 1 Chapters 1-13. Kentucky: Westminster John Knox Press, 2013.

Knight, George W. Adat Istiadat Alkitab \& Keunikannya Dalam Gambar. Jakarta: BPK Gunung Mulia, 2015.

Leks, Stefan. Tafsir Sinoptik: Tafsir Injil Matius. Yogyakarta: Kanisius, 2003.

Gering, Howard M. Analisa Alkitab. Jakarta: Yayasan Pekabaran Injil Immanuel, 1992.

Marshall, I. Howard. New Testament Theology. United Stated of America: InterVarsity Press, 2004.

Melani. "Delapan Ucapan Bahagia: Matius 5:3-12." Jurnal Theologia Aletheia 12, No. 21 (September 2010):81-97. Diakses 21 Juni 2018. http://sttaletheia.ac.id/?page_id=1092

Morris, Leon. Tafsiran Pilihan Momentum: Injil Matius. Surabaya: Penerbit Momentum, 2016.

Osborne, Grant R. Zondervan Exegetical Commentary On The New Testament: Matthew Michigan: Zondervan, 2010.

Panggarra, Robi. "Kerajaan Allah Menurut Injil-Injil Sinoptik” Jurnal Jaffray 11, No. 1 (April 2013):109-128. Diakses 21 Juni 2018.

http://ojs.sttjaffray.ac.id/index.php/JJV71/article/view/74 
Pfeiffer, Charles F., Harrison F. Everett. The Wycliffe Bible Commentary-Volume 3 Perjanjian Baru: Matius-Wahyu. Malang: Gandum Mas, 2008.

Rumante, Simon. "Teologi Biblika Perjanjian Baru Tentang Hakim Yang Akan Datang: Kajian Tentang Eskatologi Dalam Perjanjian Baru Dan Implementasinya Dalam Pendidikan Agama Kristen Di Sekolah" Jurnal Jaffray[Online], Volume 9 Number 1 (3 April 2011)

Ryken, L., James C. Wilhoit, Tremper Longman III. Kamus Gambaran Alkitab. Surabaya: Momentum, 2011.

Stassen, Glen H., David P. Gushee. Etika Kerajaan: Mengikut Yesus Dalam Konteks Masa Kini. Surabaya: Momentum, 2013.

Stott, John R.W. Khotbah di Bukit. Jakarta: Yayasan Komunikasi Bina Kasih, 2008.

Strauss, Mark L. Four Portraits, One Jesus: An Introduction To Jesus And The Gospel. Michigan: Zondervan, 2007.

Suawa, Ferdinan K. Memahami Gramatika Dasar Bahasa Yunani Koine. Bandung: Kalam Hidup, 2009.

Subekti, Timotius. Khotbah Tuhan Yesus: Pembentukan Karakter Ilahi. Yogyakarta: Andi Offset, 1986.

Suharyo, I. Pengantar Injil Sinoptik. Yogyakarta: Penerbit Kanisius, 1995.

Sutanto, Hasan. Hermeneutik Prinsip dan Metode Penafsiran Alkitab. Malang: Seminari Alkitab Asia Tenggara, 1998.

Sutoyo, Daniel, “Allah Memanggil Umat-Nya Untuk Menjadi Gereja Yang Tekun Berdoa Menurut Kisah Para Rasul 4:23-31”DUNAMIS: Jurnal Teologi dan Pendidikan Kristiani 1, No. 1 (Oktober 2016):52-73. Diakses 20 Februari 2018. http://www.sttintheos.ac.id/ejournal/index.php/dunamis/article/viewFile/101/97

T, Adhi. Perjalanan Spritual Seorang Kristen Sekuler: Enam Alasan Mengapa Saya Tetap Menjadi Kristen (Jakarta: BPK Gunung Mulia, 2008).

Tenney, Merril C. Survei Perjanjian Baru. Malang: Penerbit Gandum Mas, 2017.

Tumanan, Yohanis. "Disiplin Gereja Berdasarkan Injil Matius 18:15-17 Dan Implementasinya Dalam gereja Masa Kini" Jurnal Jaffray [Online], Volume 15 Number 1 (11 March 2017) 